\title{
IDENTIFICAÇÃO E CATEGORIZAÇÃO DOS STAKEHOLDERS DE UMA ORGANIZAÇÃO DO TERCEIRO SETOR
}

IDENTIFICATION AND CATEGORIZATION OF THE STAKEHOLDERS FROM AN ORGANIZATION OF THE THIRD SECTOR

IDENTIFICACIÓN Y CLASIFICACIÓN DE LOS ACTORES DE UNA ORGANIZACIÓN DEL TERCER SECTOR

\section{Daiane Aparecida de Melo Heinzen}

Mestre em Administração pela Universidade do Vale do Itajaí - UNIVALI

Professora do Instituto Federal de Santa Catarina - IF/SC

E-mail: dheinzen@ifsc.edu.br (Brasil)

\section{Carlos Ricardo Rossetto}

Doutor em Engenharia de Produção pela Universidade Federal de Santa Catarina - UFSC

Professor da Universidade do Vale do Itajaí - UNIVALI

E-mail: rossetto@univali.br (Brasil)

\section{José Roberto Altoff}

Mestre em Administração pela Universidade do Vale do Itajaí - UNIVALI

Professor da Universidade do Vale do Itajaí - UNIVALI

E-mail: jraltoff@fameg.edu.br (Brasil) 


\section{IDENTIFICAÇÃO E CATEGORIZAÇÃO DOS STAKEHOLDERS DE UMA ORGANIZAÇÃO DO TERCEIRO SETOR}

\section{RESUMO}

O presente artigo tem por objetivo identificar quais são os stakeholders mais relevantes que uma Organização Não Governamental compreende como atuantes em sua rede de conexões, bem como identificar o tipo de influência que estes atores exercem sobre a organização. Para tal, adotou-se como base o modelo de identificação e classificação proposto por Almeida, Fontes Filho e Martins (2000). Trata-se de uma pesquisa qualitativa e descritiva, em que se utilizou a estratégia de estudo de caso com entrevista focalizada. A coleta de dados foi realizada através de entrevista focalizada. $\mathrm{O}$ artigo apresenta um grupo de quinze potenciais stakeholders da organização, classifica cada um destes atores de acordo com sua influência sobre a organização e faz a identificação dos agentes. Os resultados mostram que todos os stakeholders que são compreendidos como influenciadores dos inputs da organização são também vistos como influenciados pelos seus outputs, o que caracteriza certo grau de interdependência entre suas atividades. $\mathrm{O}$ artigo mostra ainda quatro tipos distintos de categorias de atores: discricionários, exigentes, irrelevantes e dependentes. Verifica-se uma predominância de atores classificados como discricionários, os quais se caracterizam pelo alto grau de reconhecimento de suas ações, porém não demonstram grande significância no grau de poder exercido sobre as ações.

Palavras-chave: Organização não Governamental; Identificação de Stakeholders; Classificação de Stakeholders.

\section{IDENTIFICATION AND CATEGORIZATION OF THE STAKEHOLDERS FROM AN ORGANIZATION OF THE THIRD SECTOR}

\section{ABSTRACT}

The current article aims at identifying which are the most relevant stakeholders that a NonGovernmental Organization understands as active on its connections net, as well as identifying the type of influence that these actors practice over the Organization. It is about a quantitative and descriptive research, where it has been used the case study strategy with focused interview. The data collection was carried on through a focused interview. The article presents a group of fifteen potential stakeholders of the organization, classifies each of these actors according to its influence over the organization and identifies the agents. The results show that all the stakeholders that are understood as influencers of the organizations inputs are also seen as influenced by their outputs, which characterizes a certain degree of Independence amongst its activities. The article yet shows four distinct types of actors' categories: discretionary, demanding, irrelevant and dependent. It is verified a predominance of actors classified as discretionary, the ones that are characterized by the high level of their actions recognition, but do not show great meaningfulness on the level of power practiced over the actions.

Keywords: Non-Governmental Organization; Identification of Stakeholders; Classification of Stakeholders. 


\section{IDENTIFICACIÓN Y CLASIFICACIÓN DE LOS ACTORES DE UNA ORGANIZACIÓN DEL TERCER SECTOR}

\section{RESUMEN}

Este artículo tiene como objetivo identificar cuáles son los grupos de interés más relevantes que una organización no gubernamental que comprende como activo en sus conexiones de red, así como la identificación del tipo de influencia que estos actores tienen en la organización. Con este fin, hemos adoptado el modelo como base para la identificación y la clasificación propuesta por Almeida Filho y Martins Fontes (2000). Se trata de un salto cualitativo y descriptivo, que utiliza la estrategia de estudio de caso centrado entrevista. La recolección de datos se realizó a través de entrevistas centrado. El artículo presenta un grupo de quince posibles partes interesadas de la organización, clasifica a cada uno de estos actores en función de su influencia en la organización y hace que la identificación de los agentes. Los resultados muestran que todas las partes interesadas se entienden como influir en las entradas de la organización también son vistos como la influencia de sus productos, lo que caracteriza el grado de interdependencia entre las actividades. El artículo también muestra cuatro categorías de actores: discrecional, exigente, dependiente e irrelevante. Hay un predominio de los agentes clasificados como discrecional, que se caracterizan por un alto grado de reconocimiento de sus acciones, pero no mostró una gran importancia en el grado de poder que se ejerce sobre las acciones.

Palabras-clave: Organización no Gubernamental; Interesados Identificar; Clasificación de las Partes Interesadas. 


\section{INTRODUÇÃO}

É notável o surgimento acentuado de organizações sem fins lucrativos e não governamentais nos últimos anos, e este fenômeno pode facilmente ser identificado em todos os cantos do planeta (SALAMON,1998). Sociedades empenham-se em criar organizações com o intuito de prestar serviços à comunidade, promover o desenvolvimento econômico local e a utilização sustentável do meio ambiente, defender os direitos civis ou suprir outras carências ainda não atendidas pelo Estado. Em virtude da repercussão e eficiência de seus projetos em atividades voluntárias e dos notáveis resultados a partir deles obtidos, as ONG's vêm ganhando importância e espaço.

Como resultado deste movimento, o meio científico também passou a prestar maior ênfase em estudos que tentam entender e explicar o funcionamento das organizações que atuam neste setor da sociedade. As primeiras dissertações começam a surgir no ano de 1994 e, dois anos mais tarde, são registradas as primeiras teses de doutorado. Entretanto, é entre os anos de 2006 e 2009 que se registra o maior número de trabalhos focados nesta área, tendo maior concentração em estudos voltados às áreas de administração, contabilidade e turismo (VIEIRA, 2011). A atuação das ONG's poderá se tornar ainda mais significativa na medida em que estas puderem contar com assessoria e orientação de profissionais especializados, adequadamente qualificados e genuinamente dispostos a participar desse movimento.

Por decorrência do aumento significativo em volume e importância destas organizações é que se constituiu este estudo, tendo por objetivo identificar quais são os stakeholders mais relevantes que uma Organização Não Governamental, instalada na região norte de Santa Catarina, percebe como atuantes em sua rede de conexões, bem como identificar o tipo de influência que estes atores exercem sobre a organização, a partir da percepção dos seus gestores principais. Adotou-se como base para este estudo o modelo de identificação e classificação de stakeholders proposto por Almeida, Fontes Filho e Martins (2000).

Mediante a tentativa de se propor instrumentos de gestão para uma organização do terceiro setor, Brandão, Silva e Gudagnin (1998) apontam para a utilização de modelos adotados por empresas que são classificadas como do segundo setor. Esta extrapolação de conhecimento, segundo os mesmos autores, justifica-se pelo fato das empresas "formais" já apresentarem planos e modelos um tanto quanto consolidados, e que demonstram capacidade de adaptação a esta nova demanda social.

Tais modelos de administração, apesar de suas peculiaridades direcionadas às organizações que objetivam a geração de lucros, podem demonstrar relevância no processo de gestão a esta 
emergente categoria organizacional. Neste sentido, compreender e monitorar a rede de relacionamentos de uma organização não lucrativa pode ser vital para a manutenção das suas atividades, uma vez que as próprias ONGs, frequentemente, representam algumas das forças ou resistências que agem sobre aquelas entidades vistas como tradicionais.

Estudos sobre a importância dos stakeholders já fizeram parte dos trabalhos de Rossetto e Cunha (1999) quando pesquisaram “a importância dos stakeholders no processo de adaptação estratégica: um estudo de caso na indústria da construção civil”. Os resultados mostraram que os governos, em todos os seus níveis, possuem forte influência no processo de adaptação estratégica, além de haver influência de outros stakeholders.

Mitchell et al. (2011) também estudou a teoria dos stakeholders com o objetivo de identificar a importância dos stakeholders através da empresa familiar. Nas "entrelinhas" do artigo entende-se que a identificação da importância dos stakeholders poderá ser aplicada em qualquer segmento econômico.

Importante salientar a contribuição que o artigo oferece em função do que argumentam Laplume, Sonpar e Litz (2008) quando colocam que futuros estudos sobre stakeholders deveriam olhar para outros tipos de organizações, incluindo aquelas sem fins lucrativos e os pequenos negócios. Eles argumentam que a maioria dos estudos (82\% deles) são realizados em grandes empresas de capital aberto e que estas não são representativas da população de empresas e os seus resultados não deveriam ser generalizados para outros contextos organizacionais que são caracterizados por diferentes dotes de recursos e restrições ambientais, como é o caso das empresas estudadas aqui.

\section{MARCO TEÓRICO}

\subsection{STAKEHOLDERS: INFLUÊNCIA E IMPORTÂNCIA}

Segundo pesquisa realizada por Freeman, Phillips (2002), o uso do termo stakeholder nasceu nos anos 60, a partir de um trabalho pioneiro no Stanford Research Institute. Tais estudos afirmavam que os gerentes precisavam entender os interesses dos acionistas, empregados, clientes, fornecedores, instituições financeiras e a sociedade, para em seguida, desenvolver propostas de estratégias de negócios.

Para Bowen (1957), stakeholders são parceiros da empresa, termo abrangente que procura explicitar os graus de comprometimento e de dependência recíproca da empresa com os seus 
diversos públicos. Outra possibilidade para definir stakeholders é segundo o grau de importância relativa que têm, ou seja, quão importante é o stakeholder A em relação ao stakeholder B (Starik, 1993). Para relativizar, alguns critérios são estabelecidos: Freeman (1984) usa o critério da cooperação e competitividade.

Freeman e Reed (1983) propõem duas definições de stakeholder: em sentido amplo, o qual inclui grupos que são amigáveis ou hostis, e em sentido limitado, o qual captura a essência da definição da responsabilidade social, mas é mais específico. O sentido amplo dos stakeholders converge para qualquer grupo ou indivíduo identificável que possa afetar a realização dos objetivos organizacionais ou quem é afetado pela realização de objetivos organizacionais. Já no sentido limitado significa qualquer grupo ou indivíduo identificável dos quais a organização é dependente para que continue sobrevivendo.

Outros autores utilizam uma definição mais restrita (BOWIE, 1988;HILL; JONES, 1992; NÄSI, 1995), entendendo stakeholders como atores - ou categorias de atores tais como empregados, gerentes, fornecedores, proprietários e clientes - portadores de interesses e expectativas sobre a organização sem os quais a organização não seria possível. Além de possibilitar um conjunto estreito ou amplo como definição, sua localização pode se dar em nível de país, e das práticas de relacionamento de suas organizações com a sociedade em geral. Assim, por exemplo, Thompson et al. (1991) denomina stakeholder a qualquer ator - pessoa, grupo, entidade - que tenha uma relação ou interesses - diretos ou indiretos - com ou sobre a organização. Clarkson (1994; 1995) define stakeholders como pessoas ou grupos que têm ou reivindicam posse, direitos ou interesses em uma organização.

A partir daí, surge uma gama de conceituações acerca do termo stakeholders. As diversas definições de stakeholders variam segundo uma orientação geral semelhante, conforme afirmam Donaldson e Preston (1995, p.01):

[...] alguém olhando dentro desta grande e envolvente literatura com um olhar crítico observará que o conceito de stakeholder, modelo de stakeholder, gerenciamento de stakeholder e teoria de stakeholder são explicados e usados por vários autores de maneiras diferentes e criticados com freqüentes evidências e argumentos contraditórios.

Já Mitchell, Agle e Wood (1997) propõem definir o princípio de quem e o que realmente conta na identificação de stakeholders a partir de três atributos: a) poder para influenciar a firma, b) a legitimidade destas relações e c) o impacto de suas exigências sobre a organização. Atkinson e Waterhouse (1997) propõem que os stakeholders sejam classificados em primários e secundários. Os primários seriam aqueles sem os quais a organização não sobreviveria (os acionistas, empregados, fornecedores e consumidores). Os stakeholders secundários têm algum grau de 
importância, mas, contudo, sem comprometer a existência da organização (comunidade, governo e outras organizações). Dentro dessa linha, Orchis, Yung e Morales (2002) apresentam o conceito de stakeholders como grupos de interesse que se relacionam, afetam e são afetados pela organização e suas atividades.

$\mathrm{Na}$ dimensão mais ampla do conceito de stakeholders estão as contribuições que buscam estabelecer as relações a partir dos efeitos. O conceito de Freeman (1984), considerado o mais amplo, abre espaço para virtualmente qualquer pessoa ou entidade que possa afetar ou ser afetado pela organização. Com base em Freeman (1984), Starik (1993) propõe que o conceito seja estabelecido a partir do corte feito pelo pesquisador, pois o que afeta ou é afetado pela organização pode incluir todos os seres em geral. Nesta dimensão, o conceito não é passível de operacionalização e é capaz de fornecer os subsídios necessários para que administradores reconheçam e atuem no sentido de avaliar os interesses desses agentes.

Por outro lado, no nível restrito, estão as contribuições que visam definir grupos e seus interesses para a atividade econômica da organização. No contexto da relação entre a organização e seus stakeholders, Frooman (1999) declara que a resposta para o desenvolvimento dos stakeholders deve ser respondida por três perguntas gerais: quem eles são? O que eles querem? E, como eles estão tentando fazer isto? Ele sugere que as duas primeiras perguntas têm sido endereçadas pelos pesquisadores, enquanto a terceira tem sido negligenciada. Assim, Frooman investiga a terceira pergunta para entender a influência dos stakeholders sobre as estratégias das empresas, buscando compreender os fatores determinantes que influenciam na gestão estratégica.

Os estudos sobre stakeholders são apresentados sob ampla gama de enfoques. As diferenças são, basicamente, sob o grau de importância dos stakeholders para as organizações. Para autores como Atinkson e Waterhouse (1997), Shankman (1999) e Berman; Wicks; kotha e Jones (1999), a importância dos stakeholders é determinada pelo grau da sua contribuição para a performance organizacional. Segundo essa preposição, o objetivo das organizações é atender a um stakeholder em particular: os acionistas. Os demais estão presentes e são importantes à medida que possam contribuir para geração de lucros.

No outro extremo, se alinham autores como Freeman (1984), Donaldson e Preston (1995), Jones (1995), Metcalfe (1998) e Moore (1999) que consideram que o objetivo das organizações é atender aos interesses de todos os stakeholders: os acionistas são apenas mais um grupo de stakeholders cujos interesses as organizações devem atender, e não os únicos e mais importantes. Não haveria, assim, interesses mais importantes ou mais legítimos que outros. 
Assim, os estudos de (AGLE et al., 2008; DJELIC, VRANCEANU, 2006; SENDJAYA, SARROS, SANTORA, 2008;) contribuem ao investigar "como" a teoria dos stakeholders irá enfrentar os desafios de seu sucesso, abordando o estado atual e futuro dos stakeholders de forma consistente. Neste contexto, verifica-se que a teoria dos stakeholders está presente na academia há mais de 30 anos sendo pesquisada, discutida e revisada e continua a chamar atenção de inúmeros pesquisadores (LAPLUME; SONPAR; LITZ, 2008).

Salienta-se que parte da discussão do marco teórico está inserida na metodologia da pesquisa, o que facilitará a leitura e compreensão deste estudo, levando em consideração que a metodologia da pesquisa está relacionada com a teoria deste estudo, especialmente no que trata do modelo de Almeida, Fontes Filho e Martins (2000), que serve de base para a coleta e as análises.

\section{METODOLOGIA DA PESQUISA}

A abordagem utilizada para o desenvolvimento deste estudo amparou-se no modelo qualitativo de investigação. $O$ estudo qualitativo utiliza-se de uma tradição compreensiva (PATTON, 1986 apud ALVES-MAZOTTI; GEWANDSZAJDER, 1999), e parte do pressuposto que os indivíduos geram respostas a partir de suas crenças, valores, percepções e sentimentos. Esta abordagem também prega que as informações necessárias para um estudo podem ser conquistadas a partir de uma investigação interpretativa, o que demanda do pesquisador maior capacidade de compreensão sobre o tema vigente e seus afluentes, uma abordagem indutivista e também uma forma de investigação naturalística (ALVES-MAZOTTI; GEWANDSZAJDER, 1999).

Por conta das especificidades do estudo proposto, a estratégia que demonstrou maior relevância de utilização foi o estudo de caso (YIN, 2001). Este tipo de investigação propõe a análise de fenômenos ligados à relação entre unidades sociais, grupos, instituições e sociedade. Em sua abrangência, este estudo de caso apresenta aplicação pontual, objetivando compreender o fenômeno que permeia a unidade de estudo e, para isso, utilizou-se de experiências e particularidades de percepção dos integrantes daquele fenômeno para a geração de subsídios analíticos (MERRIAN et al., 2002).

Quanto ao seu propósito o estudo caracterizou-se como uma pesquisa descritiva. O modelo de amostragem utilizado para a realização deste estudo deu-se por conveniência e acessibilidade (OLIVEIRA, 2001). Este tipo de amostra é adequado para pesquisas exploratórias e também para a geração de pressupostos, porém seus resultados apresentam limitações em termos de riscos e imprecisão de afirmações. 


\subsection{COLETA E ANÁLISE DE DADOS}

Os dados utilizados para a construção desta pesquisa tiveram sua base originada, integralmente, de fontes primárias. Neste caso, foram feitas abordagens com dois dos três membros ativos da organização objeto do estudo: a fundadora e dirigente da referida organização e a responsável pelas atividades de educação ambiental e captação de recursos.

A coleta dos dados foi realizada em 2010 em dois momentos distintos. O primeiro momento objetivava a identificação dos atores percebidos como stakeholders pelos integrantes da organização. Para este estágio da pesquisa optou-se por adotar como técnica o desenvolvimento de entrevista focalizada, desenvolvida a partir de um roteiro semiestruturado para a sua execução. A entrevista focalizada é tão livre quanto a anterior; todavia, enfoca um tema bem específico, quando, ao entrevistado, é permitido falar livremente sobre o assunto, mas com o esforço do entrevistador para retomar o mesmo foco quando ele começa a desviar-se (BRITTO JÚNIOR; FERES JÚNIOR, 2011).

No segundo momento, aplicaram-se três modelos de questionários construídos com o intuito de verificar se aqueles atores previamente apontados pela entrevista realmente apresentam potenciais características para serem caracterizados como stakeholders efetivos da organização, objetivando ainda sua categorização em termos de legitimidade, urgência e poder.

Desta forma, para a mensuração do construto poder, foi aplicado o instrumento de coleta representado na Figura 1, sugerido por Almeida, Fontes Filho e Martins (2000), aos indivíduos diretamente envolvidos com as ações operacionais e estratégicas da organização avaliada. Vale lembrar que, neste caso específico, a estrutura simplificada da organização disponibilizou o contato direto com apenas dois indivíduos, sendo estes os responsáveis pelas ações, decisões e atividades de relacionamento direto da organização com os atores delimitados na primeira abordagem desta pesquisa. 
Figura 1 - Instrumento de coleta para medir o construto poder

\begin{tabular}{|c|c|c|c|c|c|c|c|c|}
\hline \multicolumn{9}{|c|}{ RECURSOS DE PODER } \\
\hline \multirow[b]{2}{*}{ GRAUS DE PODER } & \multicolumn{2}{|c|}{ Meios Coercitivos } & \multicolumn{4}{|c|}{ Meios Utilitários (recursos) } & \multicolumn{2}{|l|}{ Meios Simbólicos } \\
\hline & $\begin{array}{l}\text { Força } \\
\text { física }\end{array}$ & Armas & $\begin{array}{l}\text { Dependência } \\
\text { material ou } \\
\text { física }\end{array}$ & $\begin{array}{c}\text { Dependência } \\
\text { Financeira }\end{array}$ & $\begin{array}{c}\text { Dependência } \\
\text { Logística }\end{array}$ & $\begin{array}{l}\text { Dependência } \\
\text { Tecnológica } \\
\text { ou Intelectual }\end{array}$ & $\begin{array}{c}\text { Reconhecimento } \\
\text { ou estima }\end{array}$ & $\begin{array}{l}\text { Grau de } \\
\text { Poder }\end{array}$ \\
\hline $\begin{array}{l}\text { PESO ATRIBUTO } \\
\text { Grau de } \\
\text { Sensibilidade }\end{array}$ & & & & & & & & \\
\hline $\begin{array}{l}\text { ATOR } 1 \\
\text { Grau de Poder }\end{array}$ & & & & & & & & \\
\hline $\begin{array}{l}\text { ATOR } 2 \\
\text { Grau de Poder }\end{array}$ & & & & & & & & \\
\hline $\begin{array}{l}\text { ATOR } 3 \\
\text { Grau de Poder }\end{array}$ & & & & & & & & \\
\hline $\begin{array}{l}\text { Força física: capacio } \\
\text { Armas: capacidade } \\
\text { Dependência materi } \\
\text { Dependência Financ } \\
\text { Dependência Logíst } \\
\text { Dependência Tecno }\end{array}$ & $\begin{array}{l}\text { e de ger } \\
\text { gerar des } \\
\text { e física: } \\
\text { ra: crédit } \\
\text { a: localiz } \\
\text { gica e in }\end{array}$ & $\begin{array}{l}\text { agir com } \\
\text { ção físicé } \\
\text { téria-prim } \\
\text { lalorizaçã } \\
\text { o, distribı } \\
\text { ctual: cc }\end{array}$ & $\begin{array}{l}\text { iolência para cc } \\
\text {, equipamentos } \\
\text { de ativos } \\
\text { ão, fluxo de pro } \\
\text { ecimento, mar }\end{array}$ & $\begin{array}{l}\text { nstranger ou ret } \\
\text { e instalações } \\
\text { dutos e insumos } \\
\text { as, patentes }\end{array}$ & & & & \\
\hline
\end{tabular}

Fonte: Adaptado de: Almeida, Fontes Filho e Martins, 2000.

Cada um dos respondentes, num primeiro momento, teve que demonstrar como vê a sensibilidade da organização em relação aos diversos recursos avaliados, considerando, na sua análise, uma escala máxima de 5 (cinco) pontos. O número 1 (um) foi atribuído àquele recurso ao qual a organização não demonstra qualquer tipo de sensibilidade e o número 5 para o recurso em que a mesma se apresenta mais sensível. Esta avaliação da sensibilidade aos recursos foi utilizada, em igual nível de escalonamento, para ponderar o poder verificado em todos os atores relacionados às atividades da organização.

Feito isso, cada um dos atores identificados na entrevista focalizada foram então dispostos no mesmo questionário, e cada qual, novamente considerando uma escala de 5 pontos, foi avaliado pelos respondentes de acordo com o seu grau de domínio e capacidade de manipulação de cada um dos recursos listados.

O grau de exercício de poder foi calculado para cada um dos atores considerando-se a ponderação entre as pontuações atribuídas às dimensões, utilizando-se a totalização das considerações promovidas pelos indivíduos da própria organização pesquisada.

A variável legitimidade está diretamente relacionada à percepção da expectativa quanto às ações de um ator social. Quanto mais desejada e apropriada forem as ações de um ator, considerando-se sua aplicação dentro de um sistema socialmente constituído de normas, valores, 
crenças e definições (MARTINS; FONTES FILHO, 1999), maior será sua legitimidade, sendo a consideração inversa desta afirmativa proporcionalmente verdadeira.

Almeida, Fontes Filho e Martins (2000, p.6) apontam que "[...] a mensuração de legitimidade ocorre a partir de duas variáveis, componentes, ou graus de desejabilidade das ações do ator, para a organização (nível de legitimidade micro-social) e para a sociedade (legitimidade macro-social)".

Os respondentes deste estudo, ao avaliarem o grau de legitimidade de cada um dos possíveis stakeholders elencados previamente, tiveram que novamente considerar uma escala de 5 pontos para apontar o grau de desejabilidade das ações destes atores nas duas esferas sociais previamente mencionadas, seguindo o modelo apresentado na Figura 2.

A escala, em semelhança à utilizada para medir o construto poder, também utilizou do grau 1 (um) para determinar a ausência total de desejo para a ação do ator, e o grau 5 (cinco) para a ação com maior grau de desejabilidade. O grau total de legitimidade de cada um dos atores foi determinado através da ponderação dos graus atribuídos a eles nas duas esferas sociais.

Figura 2 - Instrumento de coleta para medir o construto legitimidade

\begin{tabular}{|c|c|c|c|}
\hline \multirow[b]{2}{*}{ Atores } & \multicolumn{2}{|c|}{ Níveis de desejabilidade } & \multirow{2}{*}{$\begin{array}{l}\text { Grau de Legitimidade Total } \\
\qquad \mathrm{GL}=\left(\mathrm{L}_{\circ}+\mathrm{L}_{\mathrm{s}}\right) / 2\end{array}$} \\
\hline & $\begin{array}{c}\text { Para a organização } \\
L_{o}\end{array}$ & $\begin{array}{c}\text { Para a sociedade } \\
L_{s} \\
\end{array}$ & \\
\hline \multicolumn{4}{|l|}{ Ator 1} \\
\hline Ator 2 & & & \\
\hline Ator $n$ & & & \\
\hline
\end{tabular}

Fonte: Adaptado de: Almeida, Fontes Filho e Martins, 2000.

A variável urgência refere-se ao grau de imediatismo que o stakeholder utiliza para exigir respostas por parte da organização. Para Almeida, Fontes Filho e Martins (2000, p.6) esta urgência nas respostas pode ser proveniente de fatores como "[...] a sensibilidade temporal da não aceitação de atraso" e/ou "a importância do clamor tendo em vista a possibilidade de dano à propriedade, sentimento, expectativa e exposição”.

Desta forma, aos respondentes foi solicitado que, para cada ator listado no instrumento responsável por medir o construto urgência, conforme Figura 3, fosse também atribuído uma pontuação relativa à mesma escala de cinco pontos utilizados nos instrumentos anteriores.

O item sensibilidade temporal está relacionado com a margem de aceitação de atraso que o stakeholder tem em relação às respostas geradas pela organização. O grau 1 (um) refere-se à total aceitação de atraso por parte do stakeholder em relação às respostas da organização, demonstrando 
flexibilidade no relacionamento. O grau 5, entretanto, deve ser utilizado para aqueles stakeholders sem nenhum tipo de tolerância a atrasos. $\mathrm{O}$ item criticalidade está relacionado à importância que se deve dar em atender prontamente aos anseios de cada um dos atores, uma vez que o cumprimento ou não dos prazos com aquele ator pode culminar em perdas significativas para a organização. Neste caso, pediu-se para que fosse atribuído grau 1 aos atores que não implicam em nenhuma perda para a organização, e 5 (cinco) para aqueles que implicam em perdas significativas, representando fatores altamente críticos.

Figura 3 - Instrumento de coleta para medir o construto urgência

\begin{tabular}{|c|c|c|c|}
\hline \multirow[b]{2}{*}{ Atores } & \multicolumn{2}{|c|}{ Critérios de urgência } & \multirow{2}{*}{$\begin{array}{l}\text { Grau de Urgência Total } \\
\qquad \mathrm{GU}=(\mathrm{S}+\mathrm{C}) / 2\end{array}$} \\
\hline & $\begin{array}{l}\text { Sensibilidade } \\
\text { Temporal - S }\end{array}$ & $\begin{array}{c}\text { Criticalidade } \\
\text { C }\end{array}$ & \\
\hline \multicolumn{4}{|l|}{ Ator 1} \\
\hline Ator 2 & & & \\
\hline Ator $n$ & & & \\
\hline
\end{tabular}

Fonte: Adaptado de: Almeida, Fontes Filho e Martins, 2000.

\subsection{O CASO ANALISADO “OBJETO DE ESTUDO”}

Para fins deste artigo, analisou-se uma Organização Não Governamental - ONG ambientalista, sem fins lucrativos. Esta ONG atua na defesa da biodiversidade através de campanhas de conscientização da população para assegurar a integridade das áreas remanescentes de mata Atlântica. As ações propostas visam não apenas a proteção do patrimônio nacional como também a proteção dos mananciais, que trazem benefícios diretos para a comunidade local, pois garante o abastecimento de água, fundamental para a continuidade do processo de desenvolvimento da região.

Esta ONG tem recebido muitas doações em dinheiro, espontâneas, de pessoas físicas, que se tornam sócias contribuintes. Este reconhecimento da sociedade é de fundamental importância para a organização cumprir sua missão.

Para Korten (1990), o termo ONG reúne quatro diferentes tipos de organizações: voluntárias, que têm uma missão social orientada por um comprometimento; contratadas de serviço público, que funcionam como empreendimentos sem fins lucrativos, mas de orientação mercantil com propósitos públicos; organizações populares, que representam os interesses dos membros, têm líder e, no geral, são auto-sustentáveis; e as "gongos", ou “ONGs governamentais", que são criadas por governos e servem para vários objetivos de política pública. 
Na América Latina, o termo ONG foi adotado para designar organizações que surgiram dos movimentos sociais e das lutas contra as ditaduras que se instalaram no continente durante os anos 60 e 70 (LANDIM, 1998; FERNANDES, 1994). Assim, de acordo com Alves (2002), o termo ONG nessa região tem uma conotação muito mais politizada do que em outras partes do mundo.

Uma parcela significativa de instituições pertencentes ao terceiro setor é denominada ONGs. Estas, segundo Fischer e Fischer (1994), também não são fáceis de definir nem caracterizar pelo fato de que elas se explicam mais por sua diversidade do que por atributos. Terceiro setor é um termo "guarda chuva" que inclui vários tipos de organizações, e o tratamento jurídico que essas organizações recebem nas estruturas legais nacionais tornam ainda mais complexa a questão de como defini-las e caracterizá-las.

A expressão "terceiro setor" começou a ser usada nos anos 70, nos EUA, para identificar um setor da sociedade no qual atuam organizações sem fins lucrativos, voltadas para a produção ou distribuição de bens e serviços públicos (SMITH, 1991).

Acerca da nomenclatura é relevante notar que, nas diferentes culturas nacionais, são encontrados termos como: "setor da caridade", "setor independente", "setor voluntário", “organizações não governamentais", "economia social", "filantropia" etc., o que cria muitas dificuldades para pesquisas que visem a estabelecer relações de semelhança entre os setores, em cada país (DIMAGGIO; ANHEIER, 1990, SALAMON, 1998.).

Apesar da dificuldade e controvérsias de definições a respeito do terceiro setor, Salamon (1998) exprime uma definição mais abrangente do tema. Para o autor, o terceiro setor é composto de: a) organizações estruturadas; b) localizadas fora do aparato formal do Estado; c) que não são destinadas a distribuir lucros auferidos com suas atividades entre os seus diretores ou entre um conjunto de acionistas; d) autogovernadas; e) envolvendo indivíduos num significativo esforço voluntário.

Ressalta-se que esse tipo de organização apresenta características peculiares às demais, elas são consideradas como espaços de manifestações de pluralismo, de variedade de expectativas, de possibilidade de realização da lógica moral e de laços não instrumentais, de participação efetiva na sociedade civil na solução dos principais entraves ao desenvolvimento sustentado dos seus paísessede (LANDIM 1993).

Assim, o terceiro setor, constituído por redes de organizações privadas, sem fins lucrativos, não governamentais e não voltadas à distribuição de lucros para acionistas e diretores, tem como características básicas atender a propósitos públicos e sociais (SALAMON, 1998). 
A importância do terceiro setor é reforçada por Grau (1998 apud BRANDÃO; SILVA; GUADAGNIN, 1998), ao considerar a sua contribuição para o desenvolvimento de um espaço público no qual necessidades coletivas sejam satisfeitas através da auto-gestão comunitária, única forma para viabilizar a retirada do Estado da produção de bens públicos, sem que deixem de ser assegurados direitos sociais.

\subsubsection{METODOLOGIA EMPREGADA PARA A IDENTIFICAÇÃO DOS STAKEHOLDERS}

Identificar e compreender os grupos de interessados nos negócios de uma organização pode representar importante instrumento para o desenvolvimento de estratégias potencialmente promotoras de vantagem competitiva à empresa (FREEMAN; MCVEA, 2001).

No mesmo sentido, ilustra-se a figura do stakeholder não como aquela exclusivamente responsável por promover limitações às ações estratégicas da organização (ANSOFF, 1965 apud FREEMAN; MCVEA, 2001). Mais que isso, ratifica-se que o suporte e o relacionamento firmado entre uma empresa e seus stakeholders possibilitam argumentos para o desenvolvimento de estratégias bem sucedidas, pois integrarão os interesses de todos os envolvidos, direta ou indiretamente no negócio, evitando a análise direcionada às limitações que as atitudes isoladas podem representar.

Freeman e Reed (1983) enfatizam ainda a importância do reconhecimento e da classificação destes grupos de interessados no negócio de uma empresa ao convergir suas análises para a representatividade destes indivíduos e seus interesses na construção de teorias gerenciais, no balizamento de um gerenciamento estratégico e também como um ponto crítico para a compreensão e análise estrutural estratégica da empresa. A sistemática a ser empregada para a identificação e classificação destes atores, entretanto, demandam habilidades pontuais de gerenciamento e de compreensão de seus níveis de influência (FROOMAN, 1999).

O modelo utilizado para a identificação dos potenciais stakeholders deste trabalho fundamentou-se na proposta tecida por Almeida, Fontes Filho e Martins (2000). Com esta tipologia de identificação dos atores foi possível gerir a investigação preliminar do estudo, que objetivava levantar junto aos envolvidos na pesquisa aqueles atores que possivelmente poderiam representar fonte de influência nas atividades desempenhadas. Esta tipologia serviu de subsídio para a construção do roteiro utilizado durante as entrevistas desenvolvidas.

Segundo Almeida, Fontes Filho e Martins (2000), os atores envolvidos nas atividades de uma organização podem ser subdivididos em 3 grupos distintos: os influenciadores dos inputs da 
organização, os influenciados pelos outputs da organização e os agentes da organização, conforme demonstrado na Figura 4. Estes grupos são organizados a partir das inter-relações que cada um dos indivíduos apresenta com a empresa, o que permite sua delimitação através da aplicação de perguntas genéricas.

Os influenciadores dos inputs são aqueles indivíduos, organismos ou empresas que, de alguma forma, são responsáveis por representar um ponto de pressão na tomada de decisão e no fluxo das atividades da própria organização. Os agentes são aqueles diretamente ligados às atividades da organização. Responsabilizam-se por manter o fluxo das atividades, por gerir a tomada de decisão e também por promover dinamicidade nas relações da organização com o seu ambiente e seus grupos de relacionamento. Os influenciados pelos outputs são aqueles que, basicamente, dependem e sofrem alterações das ações promovidas pela própria organização. Neste grupo podem ser encontrados aqueles indivíduos que são influenciados diretamente pelas ações da organização, como é o caso dos clientes e dos competidores.

Há ainda uma quarta categoria de indivíduos que podem ser identificados como stakeholders de uma organização, mas que não apresentam uma relação tão direta com as ações promovidas pela empresa. Este grupo caracteriza-se mais pela sua interação no macroambiente da organização, e acabam sendo afetados pelas alterações ambientais promovidas pela empresa: pode ser ilustrado o caso de uma comunidade, sindicatos ou de grupos de produção científica. 
Figura 4 - Potenciais Stakeholders

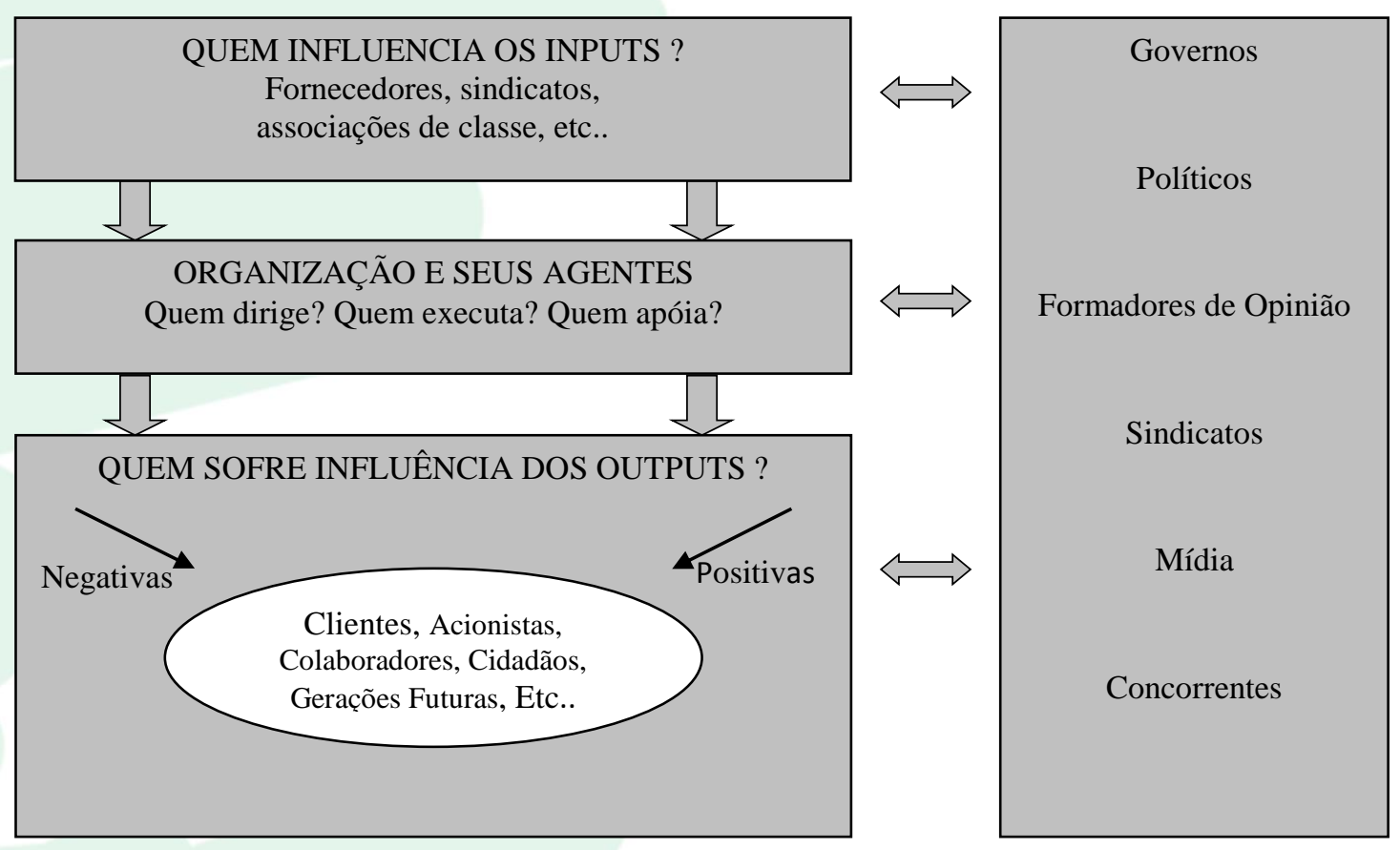

Fonte: Almeida, Fontes Filho e Martins, 2000.

\subsubsection{METODOLOGIA EMPREGADA PARA A CLASSIFICAÇÃO DOS STAKEHOLDERS}

Após identificados os atores da organização através do desenvolvimento da pesquisa focalizada, efetivou-se um novo encontro com os representantes da ONG para que se pudesse, agora, classificar cada um destes indivíduos de acordo com suas demandas e capacidades de influência.

Para tal utilizou-se das considerações e adaptações que Almeida, Fontes Filho e Martins (2000) fizeram sobre os estudos desenvolvidos por Mitchell, Agle e Wood (1997). Nesta proposta, cada um dos atores detectados previamente puderam ser, então, individualmente avaliados pela organização de acordo com uma escala de classificação para as variáveis poder, legitimidade e urgência, o que permite compreender suas ações em oito categorias principais, como demonstrando pela Figura 5.

Freeman e Phillips (2002) assinalam a inexistência de regras que imponham o tratamento igualitário a stakeholders de diferentes categorias, mas também ressaltam que a administração nas ações de relacionamento não deve considerar a aplicação de maiores esforços por conta de uma subtração daquilo que foi empregado em relacionamento com outros indivíduos.

Entretanto, para o enquadramento dos atores no rol de stakeholders de uma organização, faz-se necessário delimitar parâmetros que permitam tal intento. Campos (2003) faz um apanhado 
de referenciais demonstrando que a lente a ser utilizada para a identificação e categorização destes indivíduos pode se dar pela contribuição específica de cada intenção. Neste sentido, verifica-se maior ênfase nas propostas tecidas por Mitchell, Agle e Wood (1997), Freeman (1984), Starik (1993), Clarkson (1994) e Athkinson e Waterhouse (1997).

Figura 5 - Classificação dos Stakeholders

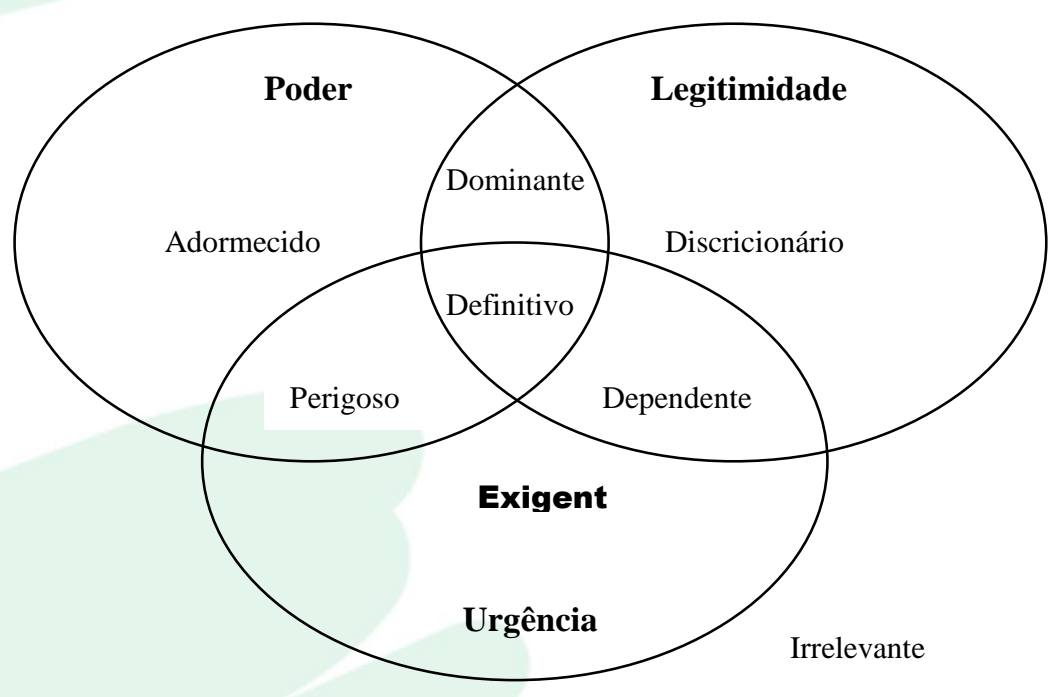

Adaptado de: Mitchell, Agle e Wood, 1997.

Cada um destes autores lança mão de conceitos apropriados aos seus estudos, e demonstram haver versatilidade no reconhecimento e categorização destes atores em contexto organizacional. Na verdade, os objetivos delimitados para cada trabalho e análise é que convergirão as escolhas do pesquisador pelo modelo mais adequado a ser adotado.

Almeida, Fontes Filho e Martins (2000) indicam que seu modelo adota:

[...] uma visão pluralista da organização ao considerar seus objetivos como uma resultante de interesses desiguais e eventualmente conflitantes. Apresenta como vantagem uma visão dinâmica, ao assumir que nem todos os atores têm desejo de exercer seu poder em todos os momentos.

As três variáveis mensuradas possibilitaram, através das suas intersecções, a formação de “casulos" que permitiram a classificação dos potenciais stakeholders. Entretanto, cada uma destas variáveis teve que ser avaliada sob um enfoque exclusivo, tendo para si um tratamento próprio e demandando instrumentos de coleta e análise de dados independentes, que respeitassem as formas e limitações de mensuração de cada um destes construtos.

A variável poder foi mensurada considerando-se a participação das partes em um jogo social, e tendo como preceito que o possível stakeholder poderia influenciar a empresa através do 
controle de algumas das fontes desta força (MATUS 1993 apud MARTINS; FONTES FILHO, 1999). Estas fontes de poder têm sua origem no controle dos recursos coercitivos (força física, armas), dos recursos utilitários (tecnologia, dinheiro, conhecimento, logística e matéria prima) e dos recursos simbólicos (prestígio, estima, carisma) e propõem que um stakeholder possa ser a entidade dominadora de uma destas fontes, submetendo, então a organização aos seus interesses.

\begin{abstract}
A classificação do grau de poder dos atores deve ser realizada segundo uma escala de disponibilidade do recurso, onde são avaliados os recursos de poder a disposição de cada ator. Para essa dimensão, o grau final será um índice composto pela sensibilidade da organização a cada um dos recursos ponderado pelo quantum deste recurso detido pelo ator (ALMEIDA; FONTES FILHO; MARTINS, 2000).
\end{abstract}

Desta forma, foram aplicados instrumentos de coleta para: mensuração do construto poder (Figura 1); medir o construto legitimidade (Figura 2); e, medir o construto urgência (Figura 3), conforme descritos no item coleta e analise de dados.

Finalmente, para se chegar à classificação definitiva dos stakeholder de acordo como o modelo ilustrado na figura5, fez-se necessária a análise comparativa de cada uma das dimensões mensuradas através dos instrumentos apresentados nas Figuras 1, 2 e 3.

A partir dos seus resultados faz-se possível a identificação de um referencial padronizado capaz de gerar comparações entre os construtos mensurados, então denominado de ponto de criticidade "k". A definição do ponto "k", de acordo com Almeida, Fontes Filho e Martins (2000, p.09), deve ser feita:

[...] a partir de função da média e desvio padrão dos conjuntos de dados relativos às avaliações de poder, urgência e legitimidade. Por exemplo, poder-se-ia definir a constante como $\mathrm{k}=\mu+\sigma$, Onde $\mu=$ a média geral dos dados e $\sigma=(\sigma \mathrm{GP}+\sigma \mathrm{GL}+\sigma \mathrm{GU}) / 3$, ou seja, a média dos desvios padrões dos três conjuntos de medições.

Com os resultados obtidos a partir dos devidos instrumentos de coleta para cada um dos atores identificados no levantamento inicial, tornou-se possível avaliar e classificar cada indivíduo a partir do ponto de criticidade " $k$ " conforme apresentado na figura 6. Este exercício foi capaz de denominar e separar cada stakeholder de acordo com suas particularidades, tendo por base suas características mais marcantes. 
Figura 6 - Dimensões e critérios para classificação dos atores

\begin{tabular}{|cc|}
\hline $\begin{array}{c}\text { Critério de análise das } \\
\text { dimensões }\end{array}$ & Classificação do ator \\
\hline$G P<k ; G U<k ; G L \geq k$ & Discricionário \\
$G P \geq k ; G U \geq k ; G L \geq k$ & Definitivo \\
$G P<k ; G U \geq k ; G L \geq k$ & Dependente \\
$G P \geq k ; G U<k ; G L<k$ & Adormecido \\
$G P \geq k ; G U<k ; G L \geq k$ & Dominante \\
$G P<k ; G U \geq k ; G L<k$ & Exigente \\
$G P \geq k ; G U \geq k ; G L<k$ & Perigoso \\
$G P<k ; G U<k ; G L<k$ & Irrelevante (não-stakeholder) \\
\hline
\end{tabular}

Fonte: Adaptado de: Mitchell, Agle e Wood, 1997.

\section{RESULTADOS DA PESQUISA}

O produto da primeira parte desta investigação, que se propunha identificar os principais atores que apresentam capacidade potencial para serem compreendidos como stakeholders da organização avaliada, findou em um rol de indivíduos e organizações que, efetivamente, apresentam relacionamento direto ou indireto com as atividades desenvolvidas pela ONG.

Neste grupo de quinze atores, apresentados na Figura 7, pode-se identificar indivíduos que são compreendidos como responsáveis por interferir ou exercer influência sobre os inputs da organização, bem como grupos de atores que podem ser, ou são, afetados pelas atividades desempenhadas pela mesma (ALMEIDA, FONTES FILHO e MARTINS, 2000). Ainda, para contribuir na construção deste agrupamento, evidencia-se a presença daqueles atores que fazem parte, efetivamente, das atividades organizacionais, e que apresentam influência no fluxo das ações desempenhadas e também nos processos de tomada de decisão, aqui denominados como agentes.

Interessante é verificar que todos os indivíduos que são compreendidos como influenciadores dos inputs da organização são também vistos como influenciados pelos seus outputs. Isto sugere ações cíclicas entre organização e ator, demonstrando certo grau de interdependência entre suas atividades. Esta dupla caracterização também pode se dar pelo alto grau de dependência que a organização apresenta em termos de recursos, e que para a garantia da manutenção de suas atividades necessita desenvolver ações que contribuam para a construção de um envolvimento saudável com seu grupo de relacionamento.

Se analisada a maior predominância dos tipos de atores por seus papéis desempenhados, percebe-se uma grande concentração naqueles caracterizados como sensíveis às ações praticadas 
pela organização. Este fenômeno talvez possa ser explicado pelo próprio propósito da organização, que objetiva conscientizar e promover mudanças de comportamento de um grupo social, considerando para isso a bandeira de um ideal ecológico de preservação. Tais atividades influenciam diversas tomadas de decisão tanto do poder público, quanto do privado, e também resultam em reações legais que propõem atividades corretivas diante de fatos já acontecidos, porém contestados pela sua caracterização contrária ao propósito ecológico defendido.

Figura 7 - Subdivisão, por papéis, dos potenciais stakeholders da organização.

\begin{tabular}{|lccc|}
\hline \multicolumn{1}{|c}{ Atores } & $\begin{array}{c}\text { Influenciadores } \\
\text { dos inputs }\end{array}$ & $\begin{array}{c}\text { Influenciados } \\
\text { pelos outputs }\end{array}$ & Agentes \\
\hline Câmaras de Vereadores & $\mathrm{X}$ & $\mathrm{X}$ & $\mathrm{X}$ \\
Conselho Diretor e Fiscal do Instituto & & $\mathrm{X}$ & \\
Empresas locais & $\mathrm{X}$ & $\mathrm{X}$ & \\
Entidades Parceiras & & $\mathrm{X}$ & \\
Estudantes do ensino médio e fundamental & $\mathrm{X}$ & $\mathrm{X}$ & \\
Mídia & & $\mathrm{X}$ & \\
Ministério do Meio Ambiente & & $\mathrm{X}$ & \\
Ministério Público (Federal e Estadual) & $\mathrm{X}$ & $\mathrm{X}$ & \\
Moradores do entorno da área de preservação & & $\mathrm{X}$ & \\
Ong's do mesmo setor & & $\mathrm{X}$ & \\
Organismos de fiscalização e controle ambiental & $\mathrm{X}$ & $\mathrm{X}$ & \\
Polícia ambiental & & $\mathrm{X}$ & $\mathrm{X}$ \\
Prefeituras locais & & & \\
Sociedade & & & \\
Voluntários e estagiários & & & \\
\hline
\end{tabular}

Fonte: originado da pesquisa empírica deste estudo

Uma vez superada a fase de identificação dos principais atores envolvidos nas atividades da organização, o presente estudo propôs-se ainda classificar cada um dos atores detectados de acordo com sua influência sobre a organização. Esta análise se deu através da avaliação de cada ator sob o aspecto de três dimensões principais: o poder exercido sobre as ações da organização, a urgência demandada nas respostas geradas e também no seu grau de legitimidade perante a sociedade e a organização.

O modelo de classificação utilizado findou na identificação exclusiva de quatro tipos distintos de categorias de atores: discricionários, exigentes, irrelevantes e dependentes, conforme Figura 8. Por suas características, os atores classificados como irrelevantes não demonstraram possuir atributos ou forças suficientes para poderem ser classificados como stakeholders da organização em estudo, uma vez que nenhuma de suas dimensões avaliadas tenha demonstrado relevância significativa mediante ao ponto de criticidade $(\mathrm{k})$ detectado na análise estatística dos resultados de todas as dimensões. 
Dois dos atores delimitados pelos membros da organização tiveram sua categorização direcionada ao grupo dos Exigentes. Estes indivíduos não apresentaram forças significantes quando analisado o seu grau de poder diante das ações da organização e demonstram também não possuir representatividade percebida em suas ações perante a organização ou a sociedade. Seu relacionamento com a organização, entretanto, demonstra-se consolidado ao explicitar a existência de condições para a geração de respostas imediatas nas ações desenvolvidas.

Mitchel, Agle e Wood (1997) sugerem que esta categoria de stakeholders pode ser analisada pela metáfora de "mosquitos zunindo em torno das orelhas dos gestores da organização": efetivamente não possuem condições de produzir grande mau, sendo relativamente inofensivos, entretanto dispõem de instrumentos que incomodam os gestores e forçam a execução de tarefas que ainda não foram cumpridas.

Figura 8 - Classificação dos atores de acordo com seu grau de urgência, legitimidade e poder

\begin{tabular}{|c|c|c|c|c|}
\hline \multirow[b]{2}{*}{ Atores } & \multicolumn{3}{|c|}{ Dimensões avaliadas em cada um dos atores } & \multirow[b]{2}{*}{$\begin{array}{c}\text { Tipo de } \\
\text { Stakeholder }\end{array}$} \\
\hline & $\begin{array}{c}\text { Grau de Poder } \\
\text { (GP) }\end{array}$ & $\begin{array}{c}\text { Grau de } \\
\text { Urgência } \\
(\mathbf{G U})\end{array}$ & $\begin{array}{c}\text { Grau de } \\
\text { Legitimidade } \\
\text { (GL) }\end{array}$ & \\
\hline Câmaras de Vereadores & 3,65 & 3,50 & 4,25 & Discricionário \\
\hline Conselho Diretor e Fiscal do Instituto & 3,60 & 4,50 & 4,00 & Exigente \\
\hline Empresas locais & 2,85 & 3,25 & 3,75 & Irrelevante \\
\hline Entidades Parceiras & 3,80 & 4,50 & 3,75 & Exigente \\
\hline Estudantes do ensino médio e fundamental & 2,80 & 3,75 & 4,50 & Discricionário \\
\hline Mídia & 3,65 & 3,50 & 4,50 & Discricionário \\
\hline Ministério do Meio Ambiente & 2,18 & 3,00 & 4,25 & Discricionário \\
\hline Ministério Público (Federal e Estadual) & 2,25 & 3,00 & 4,00 & Irrelevante \\
\hline Moradores do entorno da área de preservação & 2,40 & 3,75 & 3,00 & Irrelevante \\
\hline Ong's do mesmo setor & 2,58 & 3,50 & 3,50 & Irrelevante \\
\hline Organismos de fiscalização e controle ambiental & 2,33 & 3,50 & 3,25 & Irrelevante \\
\hline Polícia ambiental & 1,93 & 3,00 & 4,00 & Irrelevante \\
\hline Prefeituras locais & 3,58 & 4,25 & 4,25 & Dependente \\
\hline Sociedade & 3,00 & 3,75 & 2,25 & Irrelevante \\
\hline Voluntários e estagiários & 2,20 & 3,25 & 4,00 & Irrelevante \\
\hline Desvio padrão das dimensões avaliadas $-(\sigma)$ & 0,65 & 0,50 & 0,61 & \\
\hline MDP = média dos desvios padrões das dimensõe & $(\sigma \mathrm{GP}+\sigma \mathrm{GU}+\sigma \mathrm{GL}) / 3$ & & & 0,59 \\
\hline MDA = média das dimensões poder, legitimidade & urgência dos atores & & & 3,42 \\
\hline $\mathrm{PC}=$ ponto de criticidade $\mathrm{k}-(\mathrm{MDP}+\mathrm{MDA})$ & & & & 4,01 \\
\hline
\end{tabular}

Fonte: modelo adaptado Mitchell, Agle e Wood, (1997), com dados originados da própria pesquisa.

Quatro dos atores identificados puderam ser classificados pela alcunha de Discricionários. Este grupo caracteriza-se pelo alto grau de reconhecimento de suas ações mediante a própria organização ou diante da sociedade, porém não demonstram grande significância no grau de poder exercido sobre as ações ou ainda na geração de pressão relacionada ao tempo de resposta gerada. 
Habitualmente os indivíduos que são classificados nesta categoria apresentam maior relevância pelas expectativas geradas diante de resultados de cunho social e de responsabilidade, demandando ações corretas e adequadas por parte da organização (MITCHELL, AGLE e WOOD, 1997). Por mais que não haja nenhuma pressão direta para que se firme relações mais sólidas com este grupo de indivíduos, cabe ao gestor decidir sobre quão salutar e interessante para suas atividades seria o estreitamento deste relacionamento.

A última categoria de atores detectada neste estudo apontou para a existência de um único indivíduo visto como Dependente. Este tipo de stakeholder apresenta baixo grau de poder diante das ações da organização, entretanto é um forte gerador de pressão quanto à urgência na geração de respostas e também demonstra possuir relevante legitimidade diante da própria organização e da sociedade. Sua dependência justifica-se justamente na dimensão poder, onde este indivíduo precisa utilizar-se das ações dos demais stakeholders para fazer valer seus interesses (MITCHELL, AGLE e WOOD, 1997).

\section{CONSIDERAÇÕES FINAIS}

Este artigo apresenta os resultados de uma pesquisa que buscou identificar quais os stakeholders mais relevantes que uma Organização Não Governamental compreende como atuantes em sua rede de conexão, bem como identificar os tipos de influências que estes atores exercem sobre a Organização a partir da percepção dos seus gestores principais.

Para atender o primeiro objetivo desta pesquisa, apresentou-se um grupo de quinze potenciais stakeholders da organização, são eles: câmaras de vereadores; conselho diretor e fiscal do instituto; empresas locais; entidades parceiras; estudantes do ensino médio e fundamental; mídia; ministério do meio ambiente; ministério público; moradores do entorno da área de preservação; ONGs do mesmo setor; Organismos de fiscalização e controle ambiental; polícia ambiental; prefeituras locais; sociedade e voluntários e estagiários. Verificou-se que todos os indivíduos que são compreendidos como influenciadores dos inputs da organização são também vistos como influenciados pelos seus outputs. Isto sugere ações cíclicas entre organização e ator, demonstrando certo grau de interdependência entre suas atividades.

Identificados os potenciais stakeholders, classificou-se cada um dos atores detectados de acordo com sua influência sobre a organização. Esta análise se deu através da avaliação de cada ator sob o aspecto de três dimensões principais: o poder exercido sobre as ações da organização, a urgência demandada nas respostas geradas e também no seu grau de legitimidade perante a 
sociedade e a organização. O modelo de classificação utilizado findou na identificação exclusiva de quatro tipos distintos de categorias de atores: discricionários, exigentes, irrelevantes e dependentes.

Por suas características, os atores classificados como irrelevantes (oito atores) não demonstraram possuir atributos ou forças suficientes para poderem ser classificados como stakeholders da organização em estudo. Dois dos atores delimitados pelos membros da organização tiveram sua categorização direcionada ao grupo dos Exigentes. Estes indivíduos não apresentaram forças significantes quando analisado o seu grau de poder diante das ações da organização e demonstram também não possuir representatividade percebida em suas ações perante a organização ou a sociedade.

Quatro dos atores identificados puderam ser classificados pela alcunha de Discricionários. Este grupo caracteriza-se pelo alto grau de reconhecimento de suas ações mediante a própria organização ou diante da sociedade, porém não demonstram grande significância no grau de poder exercido sobre as ações ou ainda na geração de pressão relacionada ao tempo de resposta gerada.

A última categoria de atores detectada neste estudo apontou para a existência de um único indivíduo visto como Dependente. Este tipo de stakeholder apresenta baixo grau de poder diante das ações da organização, entretanto é um forte gerador de pressão quanto à urgência na geração de respostas e também demonstra possuir relevante legitimidade diante da própria organização e da sociedade.

Conforme resultados apresentados destaca-se o grupo com predominância de atores classificados como Discricionários, são eles: câmaras de vereadores, estudantes do ensino médio e fundamental, mídia e ministério do meio ambiente. Habitualmente os indivíduos que são classificados nesta categoria apresentam maior relevância pelas expectativas geradas diante de resultados de cunho social e de responsabilidade, demandando ações corretas e adequadas por parte da organização (MITCHELL, AGLE e WOOD, 1997).

Encontra-se como fator limitante deste trabalho a aplicação da pesquisa em um caso único, sendo objeto de estudo uma Organização Não Governamental no estado de Santa Catarina. Adicionalmente, os resultados foram coletados a partir da percepção dos seus gestores principais, o que pode apresentar limitações em termos de riscos e imprecisão de afirmações. Assim, recomendase que a pesquisa seja realizada também em outros estados, para que possam ser analisadas possíveis alterações deste comportamento. Outra sugestão é ampliar o número de pessoas entrevistadas a fim de maximizar a representatividade da amostra reduzindo o risco de imprecisão dos resultados. 


\section{REFERÊNCIAS}

Agle, B. R.;, Donaldson, T.; Freeman, T. R.; Jensen, M. C.; Mitchell, R. K. Wood, D. J. (2008). Dialogue: Toward Superior Stakeholder Theory. Business Ethics Quarterly, v.18(2), p. 153-19.

Almeida, G. S.; Fontes Filho, J. R.; Martins, H. (2000). Identificando Stakeholders para Formulação de Estratégias Organizacionais. In: Anais do Encontro Nacional da Associação Nacional de Pós Graduação e Pesquisa em Administração, Rio de Janeiro, RJ, Brasil, 24. ENANPAD, XXIV, 2000, Rio de Janeiro. Anais..., Rio de Janeiro, Anpad.

Alves, M. A. (2002). Terceiro Setor: as origens do conceito. Anais do Encontro Nacional da Associação Nacional de Pós Graduação e Pesquisa em Administração, Salvador, BA, Brasil, 26. In: ENANPAD, XXVI, 2002, Salvador. Anais...,Salvador, Anpad.

Alves-Mazzoti, A. J.; Gewandszanajder, F. (1999). O método nas ciências sociais. In:_. Os métodos nas Ciências Sociais e Naturais: pesquisa quantitativa e qualitativa. São Paulo: Thompson.

Atkinson, A. A.; Waterhouse, H. J.; Wells, B. R. (Spring 1997). A Stakeholder Approach to Strategic Performance Measurement. Sloan Management Review, 38(3); p. 25-37.

Berman, S. L.; Wicks, A. C.; Kotha, S.; Jones, T. M. (Oct 1999). Does stakeholder orientation matter? The relationship between stakeholder management models and firm financial performance. Academy of Management Journal, 42(5): 488- 509.

Brandão, A. O.; Silva, A. O.; Guadagnin, L. A. (1998). Das origens do Estado ao advento do Terceiro Setor. Anais do Encontro Nacional da Associação Nacional de Pós Graduação e Pesquisa em Administração, Foz do Iguaçu, PR, Brasil, 22. In: ENANPAD, XXII, 1998, Foz do Iguaçú. Anais..., Foz do Iguaçú, Anpad.

Britto Júnior, A. F., Feres Júnior, N. (2011). Evidência, Araxá, 7(7): 237-250.

Bowen, H.oward R. (1957). Responsabilidades Sociais do Homem de Negócios. Rio de janeiro: Civilização Brasileira.

Bowie, N. (1988). The moral obligations of multinational corporations. In S. Luper-Foy (Ed.), Problems of international justice: Boulder., p. 97-113.

Campos, T. L. C. (2003). Administração de Stakeholders: uma proposta metodológica para as pesquisas sobre responsabilidade social das organizações. In: Anais do Encontro de Estudos em Estratégia, 2003, Rio de Janeiro, RJ, Anais..., Rio de Janeiro: Anpad, Brasil.

Clarkson, M.; Starik, M.; Cochran, P.; Jones, T. M., et al. (Apr 1994). The Toronto Conference: Reflections on stakeholders theory. Business and Society, Chicago:, 33(1). 
Clarkson, M .B. E. (Jan 1995). A stakeholder framework for analyzing and evaluating corpora. Academy of Management. The Academy of Management Review. Briarcliff Manor, 20(1), p.92-117.

Dimaggio, P. J.; Anheier, H. k. (Aug 1990). The Sociology of nonprofit organizations and sectors. Annual Review of Sociology. 16, 137-159.

Djelic, M. L; Vranceanu, R. (2006). PoPENING THE BLACK BOX: Moral foundations of management knowledge. Business Ethics: A European Review, 15(1): 4-5.

Donaldson, T., Preston, L. E. The stakeholder theory of the corporation: concepts, evidenc. (Jan 1995). Academy of Management. The Academy of Management Review, Briarcliff Manor, 20(1): 65-91.

Fernandes, R. C. (1994). Privado, porém público: o terceiro setor na América Latina. São Paulo:, Relume - Dimara.

Fischer, R. M.; Fischer, A. L. (1994). O dilema das ONGs. Anais do Encontro Nacional da Associação Nacional de Pós Graduação e Pesquisa em Administração, Curitiba, PR, Brasil, 18. In: ANPAD, XVIII, Curitiba. Anais..., Curitiba, Anpad.

Freeman, R. E.; Reed, D. L. (Spring 1983). Stockholders and Stakeholders: a new perspective on corporate governance. California Management Review, v.25(3).: 88-106.

Freeman, R. E. (1984). Strategic Management: A stakeholdrer approach. Boston: Pitman.

Freeman, R. E.; Mcvea, J. (2001). A Stakeholder Approach to Strategic Management. Darden Business School Working Paper, 2001, n. (01-02). Disponível: em <http://ssrn.com/abstract=263511. $>$. Acessado em: 05/02/2013.

Freeman, R. E.; Phillips, R. A. (2002). Stakeholder Theory: A Libertarian Defense. Business Ethics Quarterly, 12(3): 331-349.

Frooman, J. (Apr 1999). Stakeholder Influence Strategies. Academy of Management Review, v.24(2): 191-203.

Jones, T. M.(1995). Instrumental stakeholder theory: A synthesis of ethics and economics. The Academy of Management Review, v.20(2): 404-437.

Hill, C. W.; Jones, T. M. (1992). Stakeholder-Agency Theory. Journal of Management Studies, v.29(2):131-154.

Korten, D. (1990). Getting to the 21st Century: Voluntary action and the global agenda. West Hartford, Conn: Kumarian Press. 
Landim, L.(Jun 1993). Para além do Mercado e do Estado? Filantropia e Cidadania no Brasil. Rio de Janeiro: ISER.

Landim, L. (1998). Experiência Militante - Histórias das assim chamadas ONG's. In: Landim, Ações em sociedade - militância, caridade, assistência, etc. Rio de Janeiro: NAU - Instituto e estudos da religião. (ISER).

Martins, H. F.; Fontes Filho, J. R. (Out 1999). ¿En Quién se Pone el Foco? Identificando "Stakeholders" para la Formulación de la Misión Organizacional. Revista del CLAD Reforma y Democracia;, 15: 111-140.

Merriam, S. B. and Associates et. al. (2002). Qualitative Research in Practice: examples for discussion and analysis. San Francisco: Jossey-Bass.

Metcalfe, C. (1998). The stakeholder corporation. Journal of Business Ethics, 7(1): 30-36.

Mitchell, R. K.; Agle, B. R.; Wood, D. J. (Oct 1997). Toward a Theory of Stakeholder Identification and Salience: defining the principle of who and what really counts. Academy of Management. The Academy of Management Review, 22(4): 853-886.

Mitchell, R. K.; Agle, B. R.; Chrisman, J. J.; Spence, L. J. (April 2011). Toward a Theory of Stakeholder Salience in Family Firms. Business Ethics Quarterly, 21(2): 235-255.

Moore, G. (1999). Tinged shareholders theory: or what's so special about stakeholders? Business Ethics: A European Review, v. 8(2): 117-127.

Nasi, J. (1995). What is stakeholder thinking? A snapshot of a social theory of the firm. In J. Nasi (Ed.), Understanding stakeholder thinking: 19-32, Helsinki: LSR-Julkaisut Oy.

Oliveira, T. M. V.(2001). Amostragem não Probabilística: adequação de situações para uso e limitações de amostras por conveniência, julgamento e quotas. Administração On Line, 2(3).

Orchis, M., A.; Yung, M. T.; Morales, S. C. (2002). Impactos da responsabilidade social nos objetivos estratégicos das empresas. In Responsabilidade social das empresas: Uma contribuição das universidades. São Paulo: Editora Peirópolis.

Rossetto, C. R.; Cunha, C. J. (1999). A. A importância dos stakeholders no processo de adaptação estratégica: um estudo de caso na indústria da construção civil. Anais do Encontro Nacional da Associação Nacional de Pós Graduação e Pesquisa em Administração, Foz do Iguaçu, PR, Brasil, 24. In ENANPAD, XXIV, Foz do Iguaçú. Anais... Anpad.

Salamon L.(1998). A emergência do terceiro setor - uma revolução associativa global. Revista de Administração, São Paulo, v. 33(1): 5-11. 
Sendjaya, S.; Sarros, J. C.; Santora, J. C. (2008). Defining and meansuring servant leadership behavior in organizations. Journal of Management Studies, 45(2): 402-424.

Shankman, N. A.(may 1999). Reframing the debate between agency and stakeholder theories of the firm. Journal of Business Ethics, Dordrecht, 19(4): 319-334.

Smith, D. H. (1991). Four Sectors or Five? Retaining the Member-Benefit Sector. Nonprofit and Voluntary Sector Quarterly,20(2): 137-50.

Starik, M. (1993). Is the environment an organizational stakeholder? Naturally! In J. Pasquero \& D. Collins (Eds.), Proceedings of the Fourth Annual Meeting of the International As- sociation for Business and Society: 466-471.

Thompson, J. K.; Wartick, S. L.; Smith. H. L.(1991). Integrating corporate social performance and stakeholder management: Implications for a research agenda in small business. Research in Corporate Social Performance and Policy, 12: 207-230.

Vieira, R. (2011). Produção Científica Brasileira sobre Terceiro Setor: uma análise bibliométrica e cienciométrica baseada no banco de teses da capes. 2011, 168f, Dissertação de mestrado, (Mestrado em Ciência da Informação) UFSC Universidade Federal de Santa Catarina (UFSC), Florianópolis,-SC, Brasil.

Yin, R. K. (2001). Estudo de Caso: planejamento e métodos. Porto Alegre: Bookman. 2001.

Recebido: 05/11/2012

Aprovado: 19/01/2013 